\title{
A DEM method for simulating rubber tyre
}

\author{
Zeng-Le Ren ${ }^{1,2, *}$, Yi Pik Cheng ${ }^{1}$, Xiaomin $\mathrm{Xu}^{2}$ \\ ${ }^{1}$ Department of Civil, Environmental and Geomatic Engineering, Chadwick Building, University \\ College London, Gower Street, London WC1E 6BT, United Kingdom; \\ ${ }^{2}$ Department of Engineering, University of Cambridge, Trumpington Street, Cambridge, UK, CB2 1PZ, \\ United Kingdom; \\ zengle.ren.15@ucl.ac.uk; yi.cheng@ucl.ac.uk; xx787@cam.ac.uk \\ *Correspondence: zengle.ren.15@ucl.ac.uk
}

In recent years, many researchers have discovered that recycled rubber tyres could be an economical and environmentally-friendly reinforcement material in geotechnical engineering. While the use of rubber tyre-reinforced soil has become increasingly popular, there is still a lack of a robust and systematic method to model rubber tyres when using the discrete element method (DEM) to investigate the stress-strain responses. In this paper, DEM rubber tyres are simulated by bonding regular-packed balls, and numerically tested under tensile force using the particle flow code in three dimensions $\left(\mathrm{PFC}^{\mathrm{B} D}\right)$. When comparing the effects of different packing on the sample, using Young's modulus and Poisson's ratio, it was found that only BCC (body-centredcubic) packing could achieve a Poisson's ratio of 0.5 representing no volume change during the deformation of rubber. The difference between uniaxial compression and tension simulations was also compared as well as the influences of particle overlapping, particle radius and sample aspect ratio on the mechanical response of the tyre model. Finally, the DEM parameters were set to match the experimental Young's modulus data. The DEM method for rubber tyre strips proposed in this paper could be a basis to study other rubber reinforcements such as tyre chips and shreds, irregular rubber buffings and granulated rubber.

KEYWORDS: Rubber tyre; 3D Discrete Element Method (DEM); Packing effect; Poisson's ratio; Tensile test

\section{INTRODUCTION}

The use of recycled tyres in geotechnical applications has become increasingly popular. Waste tyres can be used with soil (ASTM D6270-98) due to its advantageous physical properties such as low unit weight, high strength, high damping absorption, favourable drainage performance and high frictional resistance. As a construction material, recycled tyres are typically classified into three categories based on the particle size: granulated rubber (up to $12 \mathrm{~mm}$ ), tyre chips (12 $\mathrm{mm}-50 \mathrm{~mm}$ ) and tyre shreds $(50 \mathrm{~mm}-305 \mathrm{~mm})$. Apart from the above three forms of shredded rubber tyres, rubber buffings (or rubber fibres) derived from re-treading tyre industry are also used in civil engineering. It was found that granulated rubber tyres and rubber buffings could improve the strength of soil by optimizing the tyre content in a tyre-soil mixture. (e.g. 
Yoon, 2007; Oikonomou \& Mavridou, 2009; Edinçliler et al., 2010; Mills \& McGinn, 2010; Fu et al., 2017). In consideration of the high preparation and processing cost, reusing larger dimensions of rubber tyres to reinforce soil could be more economically favourable. Edinçliler \& Cagatay (2013), Bergado et al. (2005), Naval et al. (2014), Fu et al. (2014) demonstrated that increasing the aspect ratio of granular rubber tyres in soil mixtures led to an increase in the overall shear strength.

However, the lack of experimental and numerical investigations is preventing industry up-take. Compared with the continuum-theories based simulations, the Discrete Element Method (DEM) could be a useful alternative for the analysis of mechanical behaviour when there is large deformation of waste tyres, and relative particles' movement at its interfaces with soil particles. Lee et al. (2014) investigated the effect of volume fractions of granular tyres on tyre-reinforced soil at a range of strain levels between $1 \%$ and $16 \%$ through 2D DEM simulations of 20,000 disks. Gotteland et al. (2008), Takano et al. (2014), Perez et al. (2016), Wang et al. (2018) used 3D DEM to simulate rubber tyres to explore the micro-scale mechanisms of granular tyre-soil mixtures based on triaxial tests and direct shear tests. However, specific and convincing details about rubber tyre calibration processes, along with validation and verification are yet to be ascertained. Besides, current numerical investigations on rubber tyre-sand mixtures focus mainly on granulated rubber; and there is no DEM simulation for intermedium-scale to large-scale tyres such as tyre chips and tyre shreds.

The tensile stiffness, deformation and strength are important parameters which help understand the macroscopic properties of rubber tyres. A tensile test is commonly used to determine strength and ductility and it can be used to assess the performance of a simulated model. DEM was used to model tensile tests of aluminium (Gaugele et al., 2008; Eberhard and Gaugele, 2013) and fused silica (Andre et al., 2012). Recently, Chen et al. (2016) illustrated a systematic methodology to simulate the tensile test of high-carbon steel using DEM. However, DEM simulation on tensile tests of rubber tyres has not yet been investigated sufficiently. The main challenge for simulating rubber tyres is to maintain a Poisson's ratio of 0.5 when using the bonded particle method. Previously published work did not consider the role of Poisson's ratio on the tensile behaviour of their studied materials and could not be applied to rubber tyre simulations directly. Inspired by these studies, the key contribution and novelty in this research are to propose a 3D DEM model for rubber tyre strips, which could be a basis to study other rubber tyre reinforcements such as irregular rubber buffings and granulated rubber, tyre chips and tyre shreds.

\section{DEM MODELLING OF RUBBER TYRE}

In this study, a piece of rubber tyre (a cubic shape with a length of $10 \mathrm{~mm}$, as shown in Figure 1) was modelled by 5,488 mono-sized, regularly packed spheres (diameter $0.3 \mathrm{~mm}$ ) using $\mathrm{PFC}^{3 \mathrm{D}}$, where the linear contact bond model was adopted. Particles were initially generated in their desired positions according to the packing requirements. And then particles were attributed with both linear contact model and linear contact bond model before cycling to equilibrium. When the linear contact bond was installed 
correctly, no particle relocation was found before and after this initial equilibrium. Three different packings, including body-centred cubic (BCC), face-centred cubic (FCC) and hexagonal close-packed (HCP) structures were used to investigate their impacts on the deformation and elasticity behaviour of numerical specimen. The calibrated parameters are shown in Table 1. Both the tensile and shear contact bond strength were set to a very high value to prevent any bond failure, this limited the system to pure elastic behaviour for both loading and unloading within $15 \%$ tensile strain $(10 \%$ compressive strain) for this study. The relationship between the particle effective modulus $\left(E^{*}\right)$ and normal stiffness $\left(k_{\mathrm{n}}\right)$ at each contact is expressed as:

$$
E^{*}=\frac{2 k_{n}}{\pi R}
$$

where $\mathrm{R}=$ particle radius (Itasca, 2018). During the uniaxial tensile and compression tests, the loading rate was kept at the maximum value of $1 \mathrm{~mm} / \mathrm{s}$, such that the ratio of the unbalanced force to the mean contact force was maintained below $1 \mathrm{e}-6$, throughout the entire loading process. A measurement sphere with a diameter of $6 \mathrm{~mm}$, was used to measure the average stresses in the centre of the specimen. Sample Young's modulus $E$ was the ratio of stresses and longitudinal strain. Sample Poisson's ratio $v$ was calculated using the strains in the transverse $e_{t}$ and longitudinal $e_{l}$ directions under uniaxial force, as illustrated in Figure 1(b):

$$
v=-\frac{D-D_{0}}{D_{0}} \frac{L_{0}}{L-L_{0}}
$$

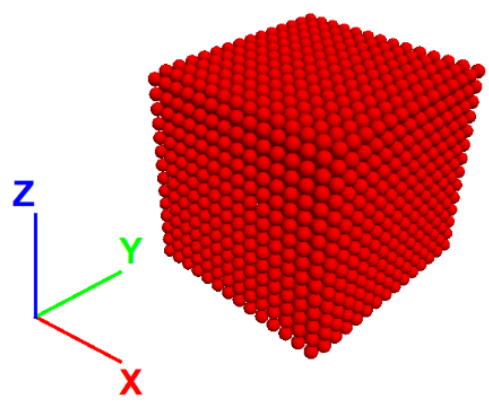

(a)

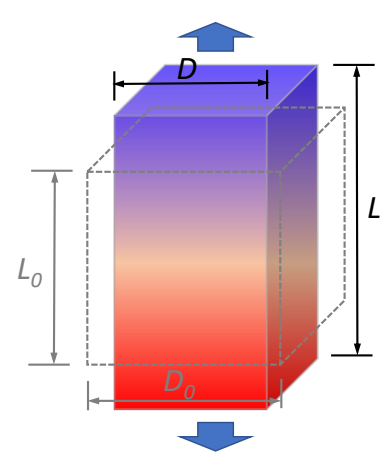

(b)

Fig. 1. DEM sample: (a) BCC packed specimen; (b) calculation of Poisson's ratio

\section{RESULTS AND DISCUSSION}

Apart from the effect of particle packing, the input parameters $E^{*}$ (particle effective modulus) and $k_{\mathrm{n}} / k_{\mathrm{s}}$ (particle normal-to-shear stiffness ratio) are the two key factors governing the deformation and elastic properties of rubber tyres. The effects of interparticle friction, tensile strength and shear strength are not significant and are thus 
ignored in this study. Figure 2 shows the evolutions of sample Young's modulus $(E)$ and sample Poisson's ratio $(v)$ of the BCC packed specimen. The results indicate that $E$ is almost constant within $1 \%$ tensile strain, and it increases slowly in the range of 5\% of tensile strain. On the other hand, sample Poisson's ratio $(v)$ is fairly constant within $5 \%$ of tensile strain. Therefore, the data used in the remainder of this paper are based on low tensile strain $(<1 \%)$. Although when tensile force was applied horizontally, it produced exactly the same stress-strain curve and Poisson's ratio, differences are expected if the numerical specimen is loaded at other directions due to the anisotropic nature of BCC packing; this is a limitation of this model.

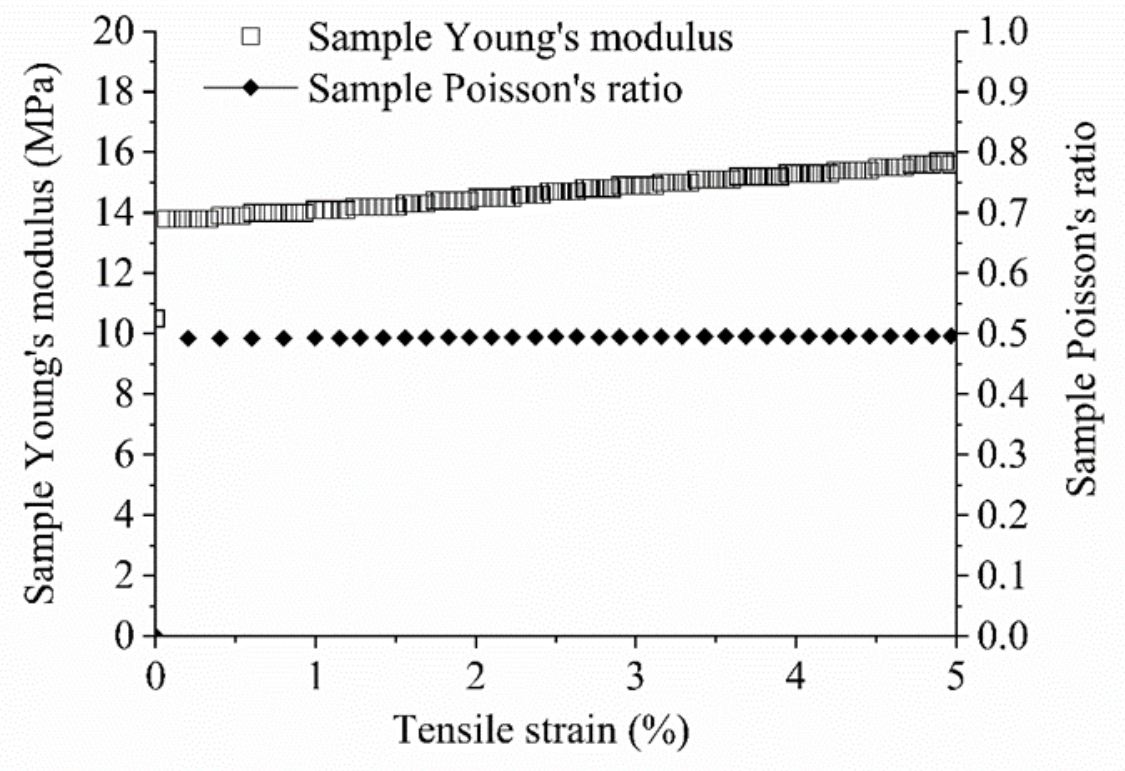

Fig. 2. Tensile properties of BCC Packing

Figure 3 shows that the values of $E$ increase linearly with $E^{*}$. However, $v$ keeps the values close to 0.5 , irrespective of the variations of $E^{*}$. For an $E^{*}$ ranging of 0.5 MPa-28 MPa, $v$ stays at 0.5 . 


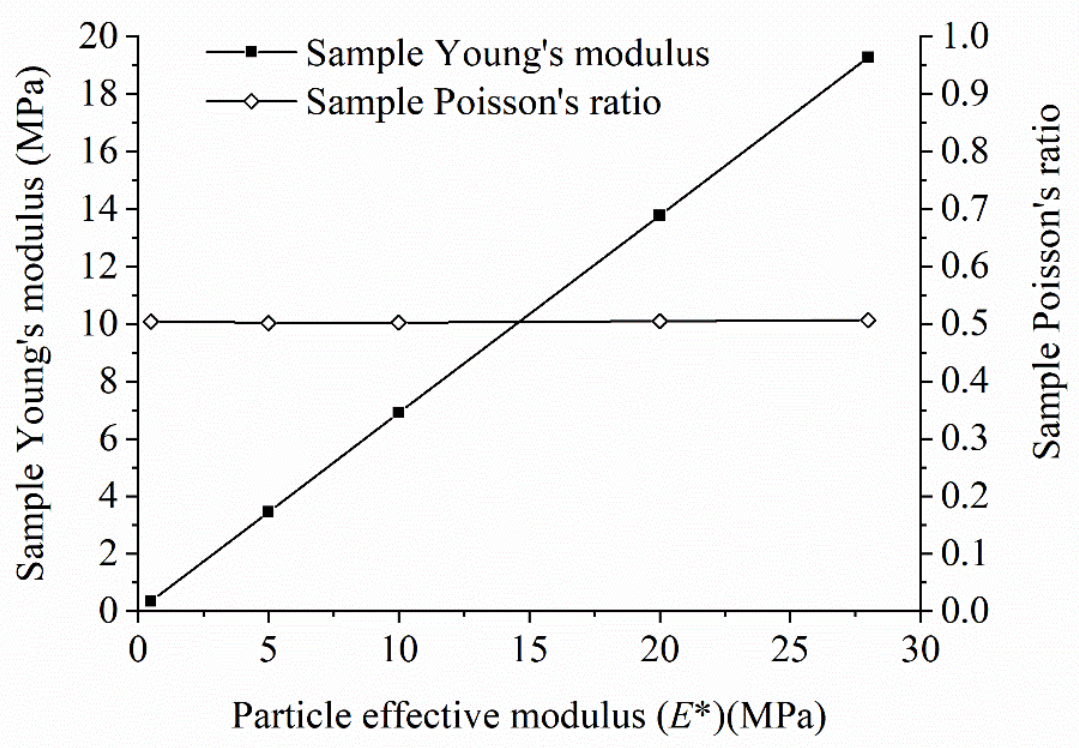

Fig. 3. Effect of particle effective modulus $\left(E^{*}\right)$ on the tensile behaviour of $\mathrm{BCC}$ packed tyre specimen

\section{Effect of different packings}

The Young's modulus and Poisson's ratio of granular materials are known to be influenced by different packings with various void fractions and void overlapping (Fleischmann et al. 2013; Heitkam et al. 2016). Each packing is associated with a certain coordination number and atomic packing factor (APF). The latter describes how efficiently atoms fill the space within a given unit cell; if the atoms are solid spheres, APF is the ratio of solid volume over the total volume of the unit cell. For example, the coordination numbers for primitive BCC, FCC and HCP closed packings are 8, 12 and 12 , and the corresponding APF values are $0.68,0.74$ and 0.74 , respectively (Yarive \& Yeh, 1984).

Figure 4 illustrates the dependence of $E$ and $v$ on different $k_{n} / k_{s}$ values for BCC, FCC and HCP packing, where the input $E^{*}$ value is $20 \mathrm{MPa}$. It can be found from Figure 4(a) that $E$ of different packings decreases to a constant with increasing $k_{\mathrm{n}} / k_{\mathrm{s}}$. It can be concluded from Figure 4 that every packing has its own range of $E$ and $v$, with the increase of $k_{\mathrm{n}} / k_{\mathrm{s}}$. Neither FCC nor HCP packing can reach a Poisson's ratio of 0.5 , whereas BCC packing can achieve the desired $E$ and $v$ values for rubber tyres. 


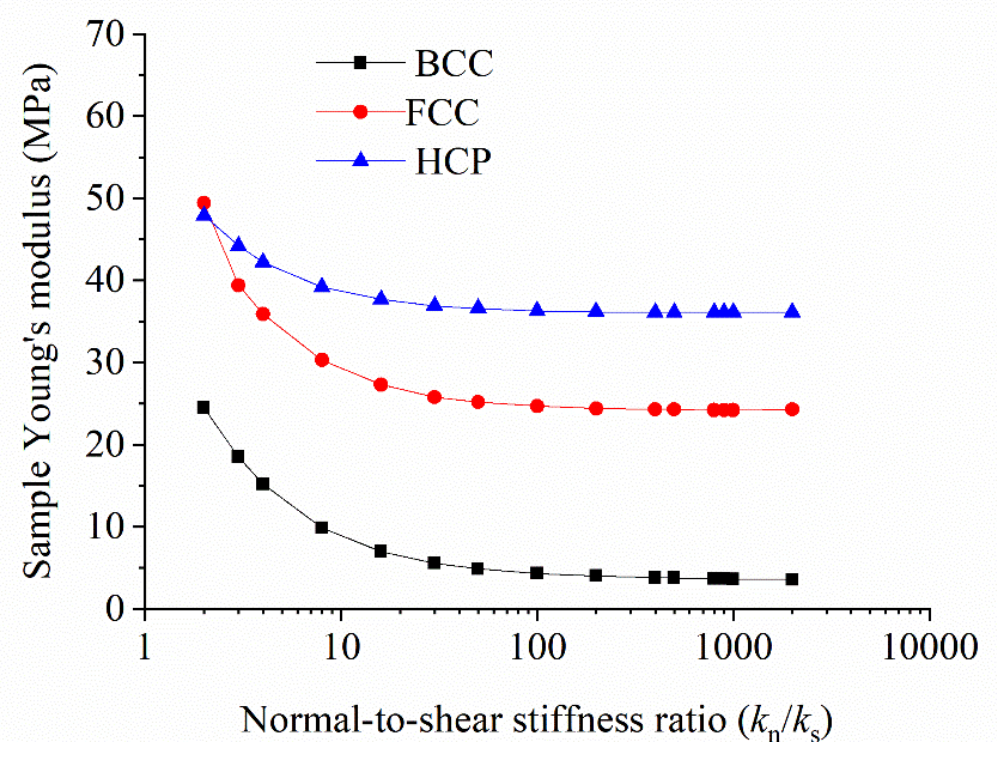

(a)

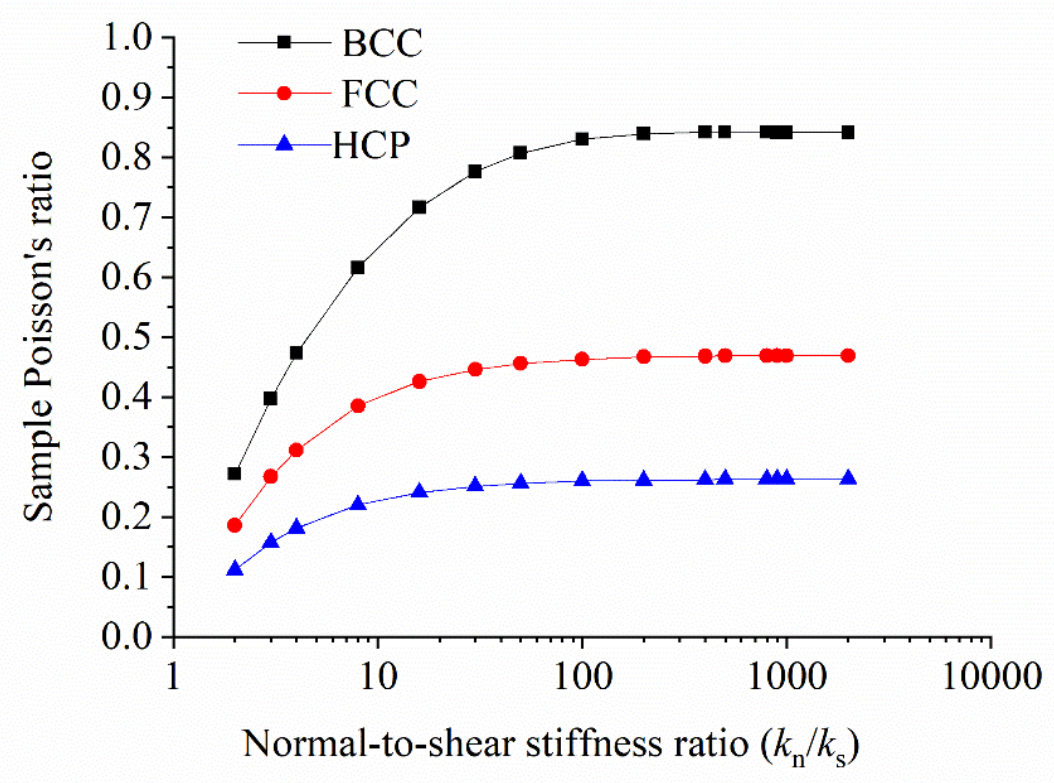

(b)

Fig. 4. Effect of different Packings: (a) Sample Young's modulus (E); (b) Sample Poisson's ratio $(v)$

Figure 5 shows the particle overlapping effect on $E$ and $v$ for BCC, FCC and HCP packing, in which the percentage of particle overlap can be defined as,

$$
\text { Overlap }=\frac{2 R-\delta}{2 R} \times 100 \%
$$


Where, $\delta=$ distance between centres of two particles. Overlap was calculated using centre particle to corner particle of a unit cell. The particles were initially created in a domain using a specific packing structure and with zero overlaps. Then, all particles were increased in radius artificially until a specific percentage of overlap was achieved. The maximum particle overlap considered is $10 \%$. $E$ for FCC and HCP packing, as shown in Figure 5(a), increase slightly with the increase of particle overlap, and $E$ for HCP packing is generally higher than that of FCC packing. However, the BCC packing shows a distinctive trend for both $E$ and $v$ within the considered range of overlap, indicating that there is a transition point at an overlap of $5.87 \%$. Figure 5(b) shows that overlap has no effect on $v$ for FCC and HCP packing within $10 \%$ overlap. FCC and HCP packing have their respective constant $v$ values of 0.33 and 0.19 . However, for BCC packing, $v$ decreases from 0.5 to 0.2 , at the same transition point when the overlap is $5.87 \%$. This transitional behaviour was found to relate to the packing structures. Further data analyses showed that, at the transition, there was a sudden increase in the coordination number from 8 to 14 as shown in Fig.5(c), which corresponds to a sudden decrease in the maximum value of particle spin and a small reduction in the maximum particle displacement. This is actually due to the corner particles of each BCC unit cell become very close to one another that increases the total number of virtual contacts of the overall system.

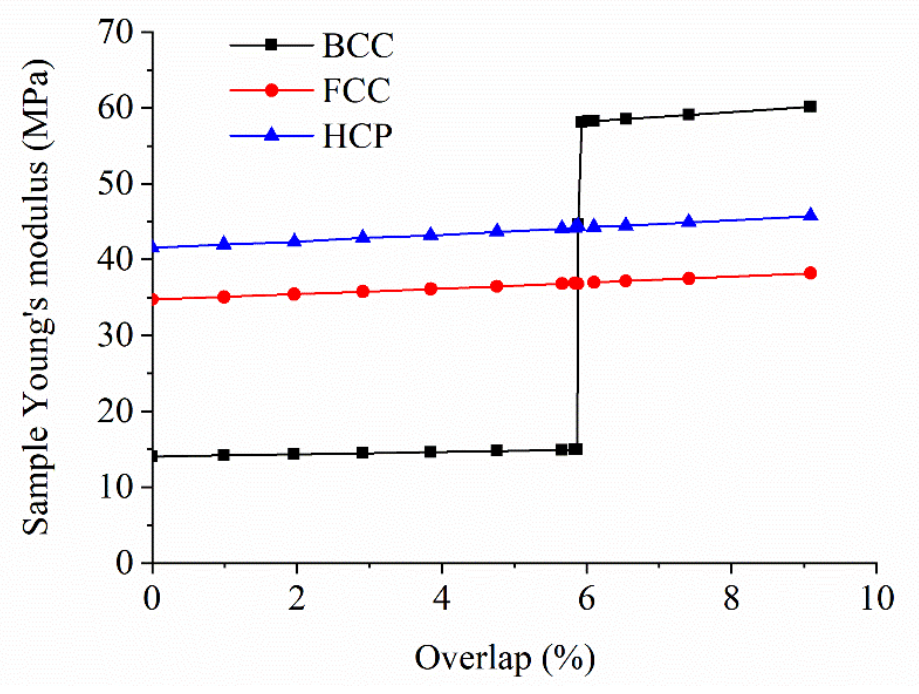

(a) 


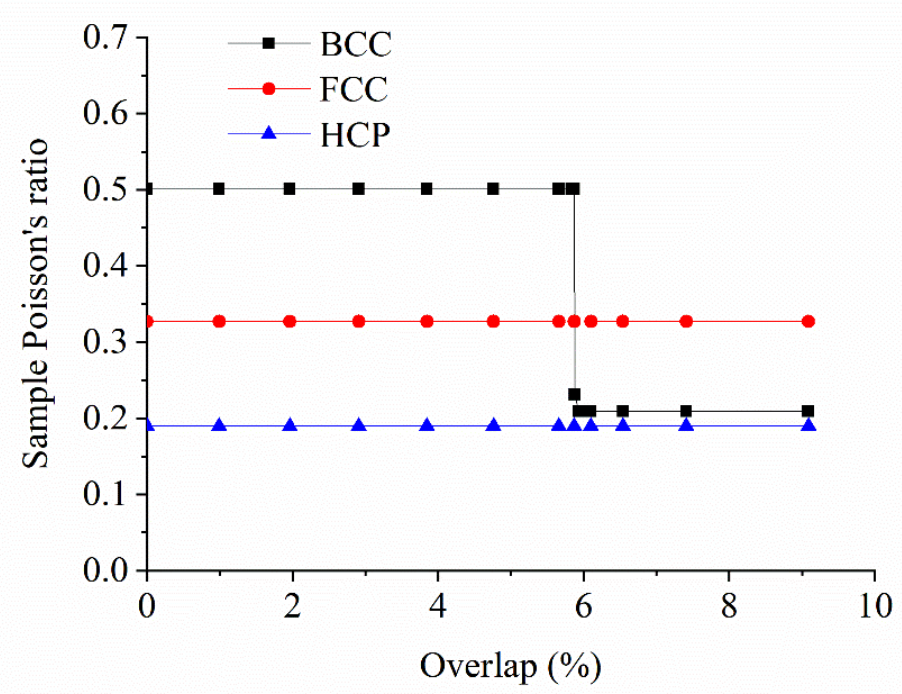

(b)

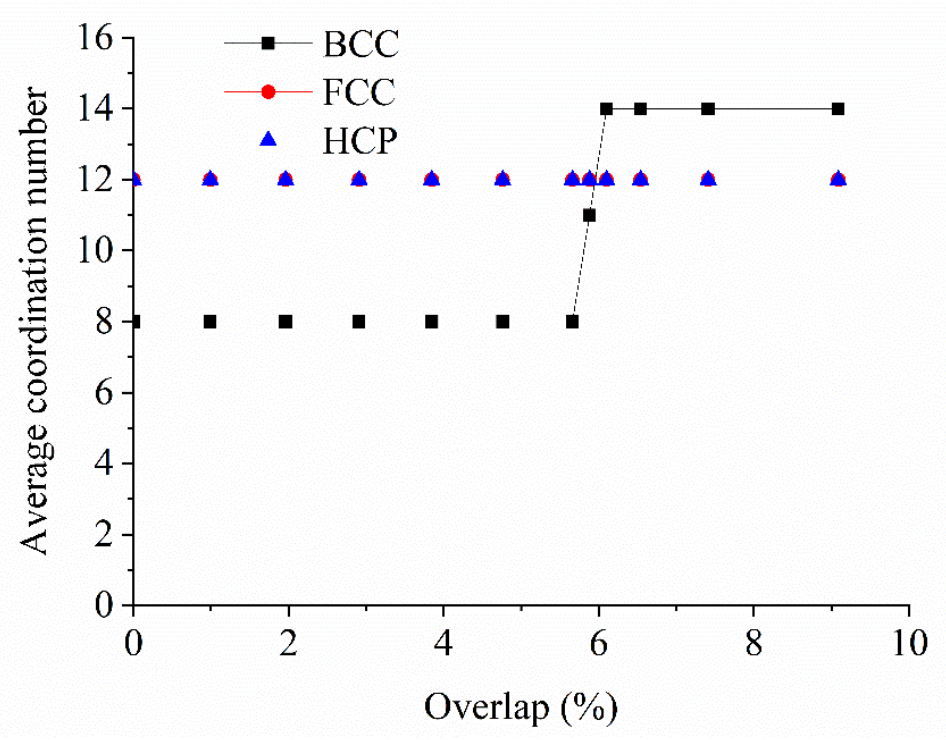

(c)

Fig. 5. Effect of particle overlap: (a) Sample Young's modulus (E); (b) Sample Poisson's ratio (v); (c) Average coordination number

\section{Compression and tension effect}

Figure 6 compares $E$ and $v$ of rubber tyres of BCC packing under both uniaxial compression and tension tests. It shows that $E$ of rubber tyres decrease slightly under compression whereas they increase slightly under tension. The small difference was caused by a localized change in void fractions of the particle arrangement under tension or compression. Figure 7(a) shows the necking at the end of $1 \%$ tension strain. Figure 7 (b) shows the bulging at the end of $1 \%$ compression strain. The sample rubber tyres have a Poisson's ratio of 0.5 under both tension and compression. 


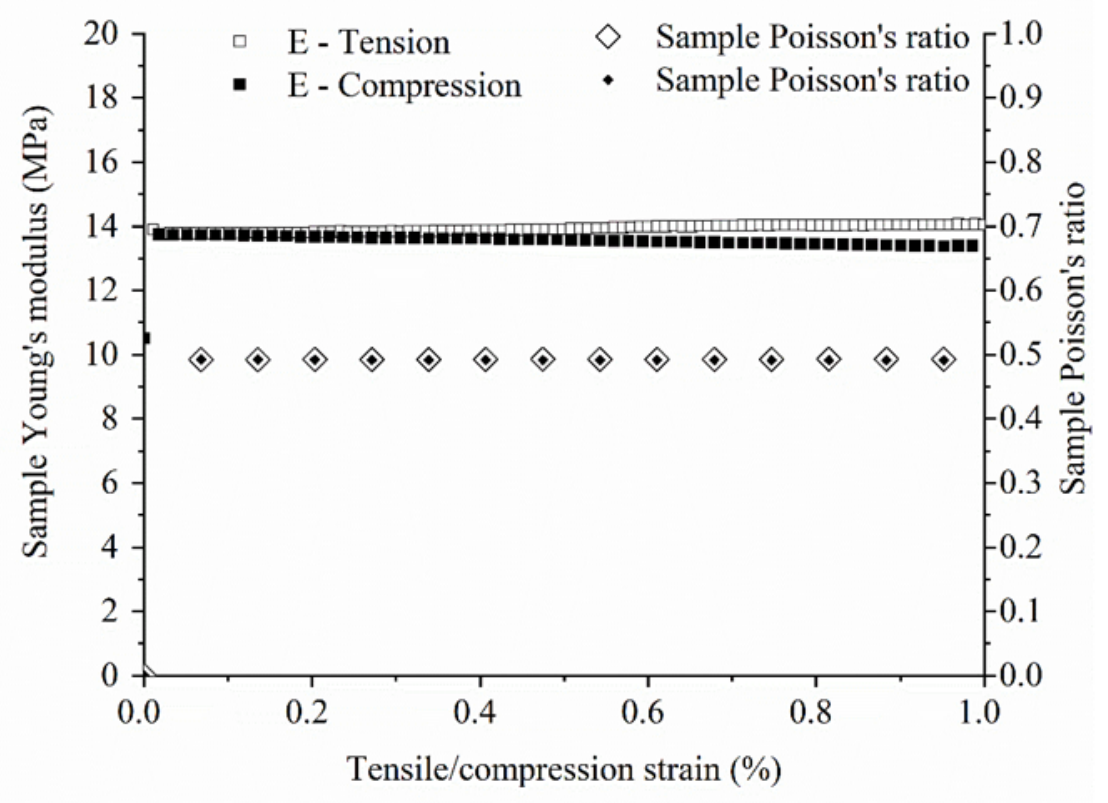

Fig. 6. Effect of compression and tension loading

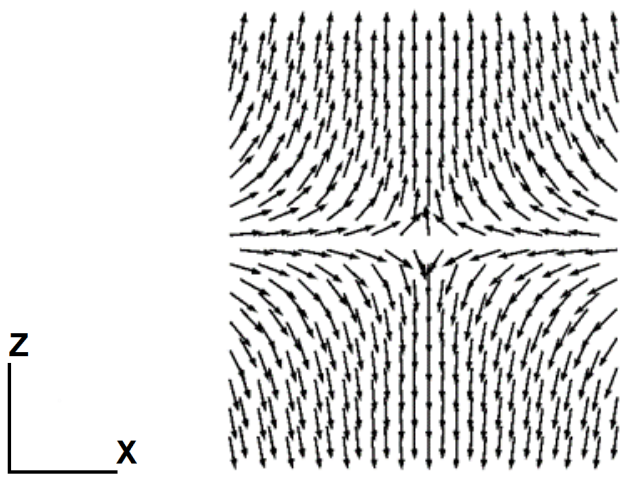

(a)

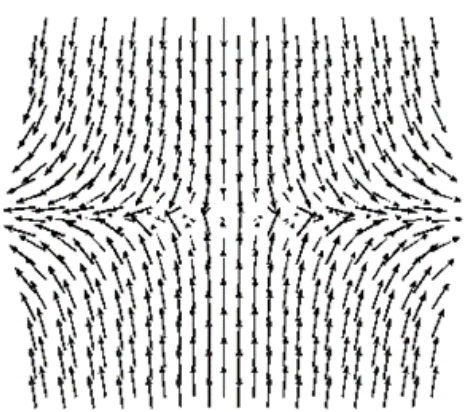

(b)

Fig. 7. Particle displacement at the end of $1 \%$ of axial strain: (a) Tension (b) Compression

\section{Particle sizes and aspect ratios}

Figure 8 shows the effect of particle radius on $E$ and $v$ of the BCC packing assembly. It shows that when the transverse length $\left(D_{0}\right)$ to particle radius $(R)$ ratio is higher than 33.3 (points A and A' as shown in Figure 8), both $E$ and $v$ stay relatively steady with a certain level of fluctuation. And there is a temporary reduction of both $E$ and $v$ between the $D_{0} / R$ ratios of 22.2 and 33.3. This may imply that, whenever computational power is allowed, this minimum number of particles across the transverse length $D_{0}$ should be targeted, in this case $D_{0} / R$ is 33.3 when particle radius $\mathrm{R}$ is $0.3 \mathrm{~mm}$, in order to achieve a stable estimation of $E$ and $v$. There are currently a handful of studies on granular 
rubber modelled using the single-particle method, where rubber particles are assigned with Poisson's ratio of 0.50 (attached to the Simplified Hertz-Mindlin contact model). However individual rubber particle's incompressibility nature was not properly modelled. It is however proposed in this paper that, when correctly calibrating an assembly of bonded particles using the BCC packing structure, this method correctly models both the mechanical and volumetric behaviour of a rubber tyre.

Figure 9 shows the influence of the sample aspect ratio of the specimen on $E$ and $v$. The rubber tyre aspect ratio is defined as the longitudinal length $\left(L_{0}\right)$ to transverse length $\left(D_{0}\right)$ ratio, as illustrated in Figure 1(b). Here, the tyre transverse length is $10 \mathrm{~mm}$, the tyre longitudinal length varies from $10 \mathrm{~mm}$ to $60 \mathrm{~mm}$, yielding to a range of aspect ratio from 1.0 to 6.0. Figure 9 shows that the dimension effect on $E$ and $v$ is minimal. This means the methodology for modelling rubber tyre proposed in this paper could be used to model intermedium-scale to large-scale tyres such as tyre chips and tyre shreds.

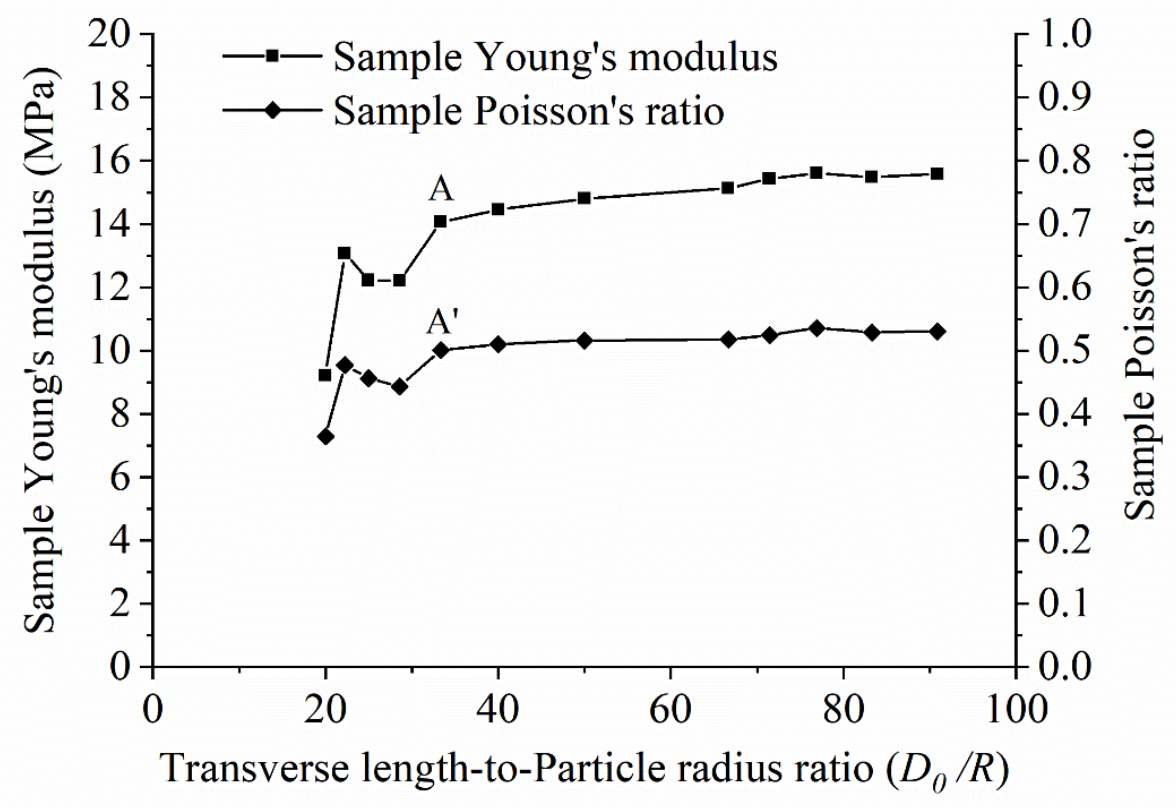

Fig. 8. Effect of particle radius on BCC Packing 


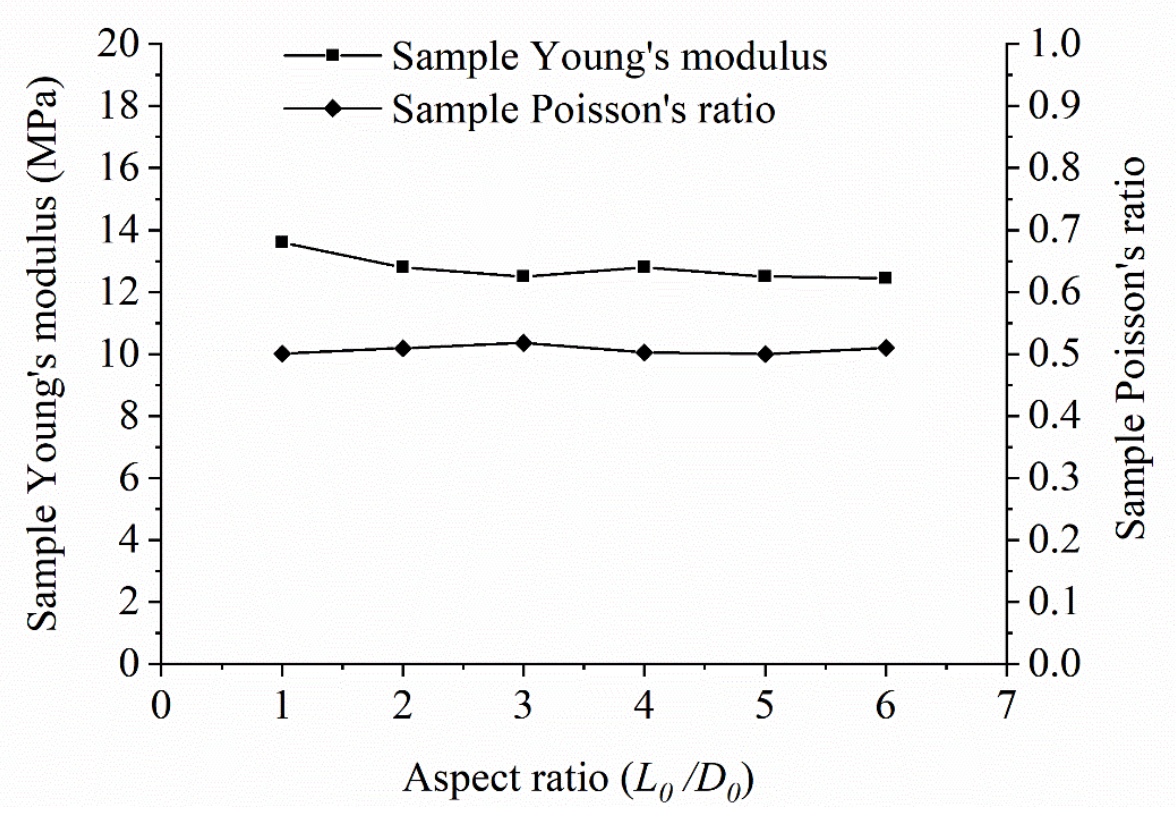

Fig. 9. Effect of specimen aspect ratio on BCC Packing

\section{Comparison with experimental results}

Figure 10 plots both the experimental data and the simulation results of Young's modulus $(E)$ and the Poisson's ratio ( $v$ ) against the tensile strain of a rubber tyre, with a tensile strain up to $15 \%$. We simulated both loading and unloading and confirmed that the model behaviour was free of plastic deformation when loading up to $15 \%$ tensile strain. The piecewise linear model proposed by Wang et al. (2014) is adopted to calibrate the nonlinear tensile behaviour of rubber tyres, including the sample Poisson's ratio. This means that the input $k_{\mathrm{n}} / k_{\mathrm{s}}$ and $E^{*}$ parameters have been iteratively artificially varied at specific ranges of tensile strain, as listed in Table 2. This is so that the simulation results match the experimental stiffness values. However, these incremental changes of input caused the maximum ratio of the average unbalanced force to contact force to increase slightly from below 1e-6 to below 1e-4 throughout the entire loading process. The experimental data here was obtained from the tensile test of a rubber tyre shred with dimensions of $10 \mathrm{~mm} \times 10 \mathrm{~mm} \times 100 \mathrm{~mm}$. Please be aware that when modelling soil-rubber interaction problems, mobilised deviatoric stress and shear strain of the tyre should be calculated. In this paper, the calibrated numerical tensile stress in Figure 10 show a good agreement with the experimental data. Also, $E$ of the rubber tyre obtained from Figure 10 is around $20 \mathrm{MPa}$, falling in the range of typical $E$ values, ranging from $4.5 \mathrm{MPa}$ to $22 \mathrm{MPa}$ obtained from other experimental tensile tests by $\mathrm{Fu}$ et al. (2014), Ratrout \& Mahmoud (2006). This DEM simulation with the chosen set of parameters satisfactorily models the properties of rubber tyres in the laboratory tests.

In order to provide a more general guidance for modelling other types of rubber tyre, a design chart is given in Figure 11. One can first obtain the initial values of normal-to-shear stiffness ratio $\left(k_{\mathrm{n}} / k_{\mathrm{s}}\right)$ and the initial $E^{*}$ value based on a desired value of $v$. In this paper, $k_{\mathrm{n}} / k_{\mathrm{s}} \approx 4.5$, and the initial $E^{*} \approx 20 \mathrm{MPa}$ as listed in Table 1 . Then, the 
incremental Young's modulus can be obtained by varying $E^{*}$ to fine tune the incremental Young's modulus, by moving vertically up/down, using different $E^{*}$ curves also shown in Figure 11.

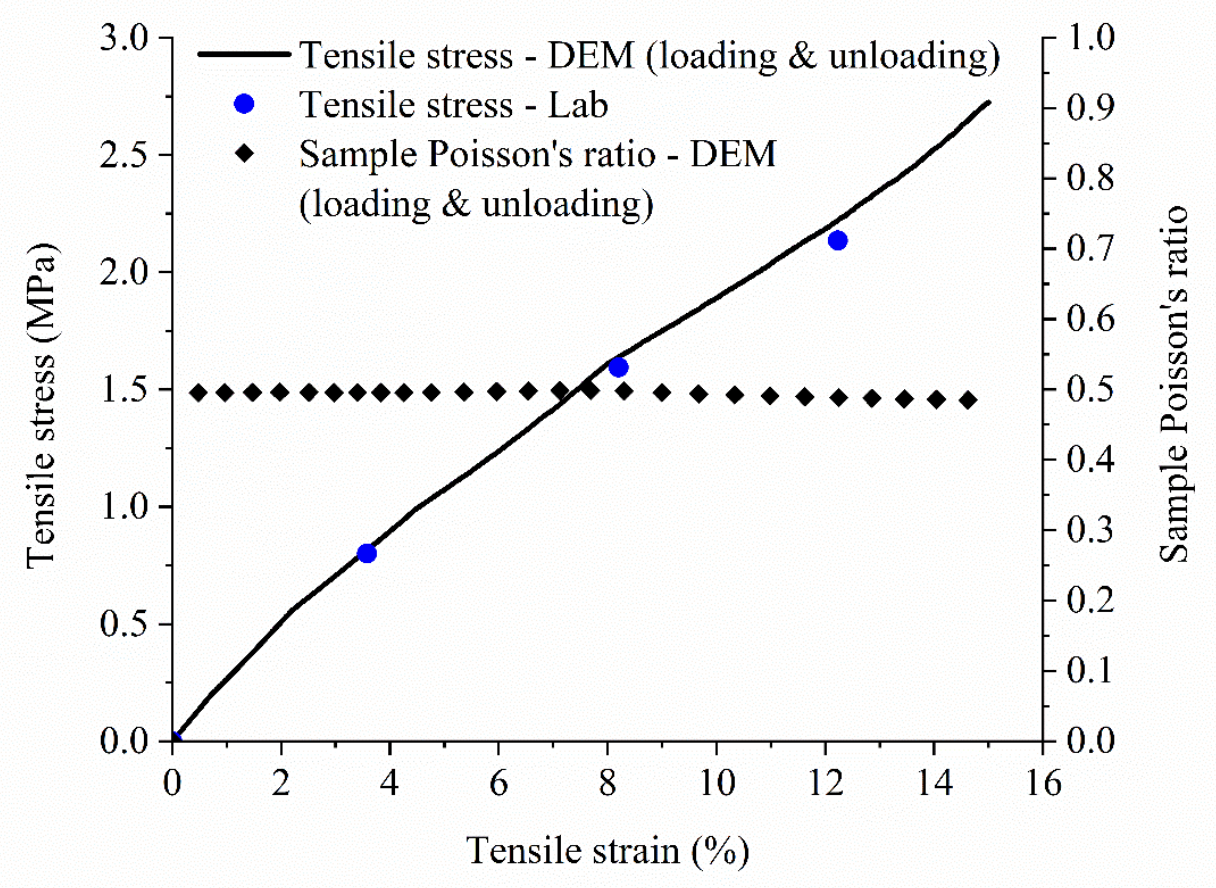

Fig. 10. Calibration results of rubber tyre tensile test

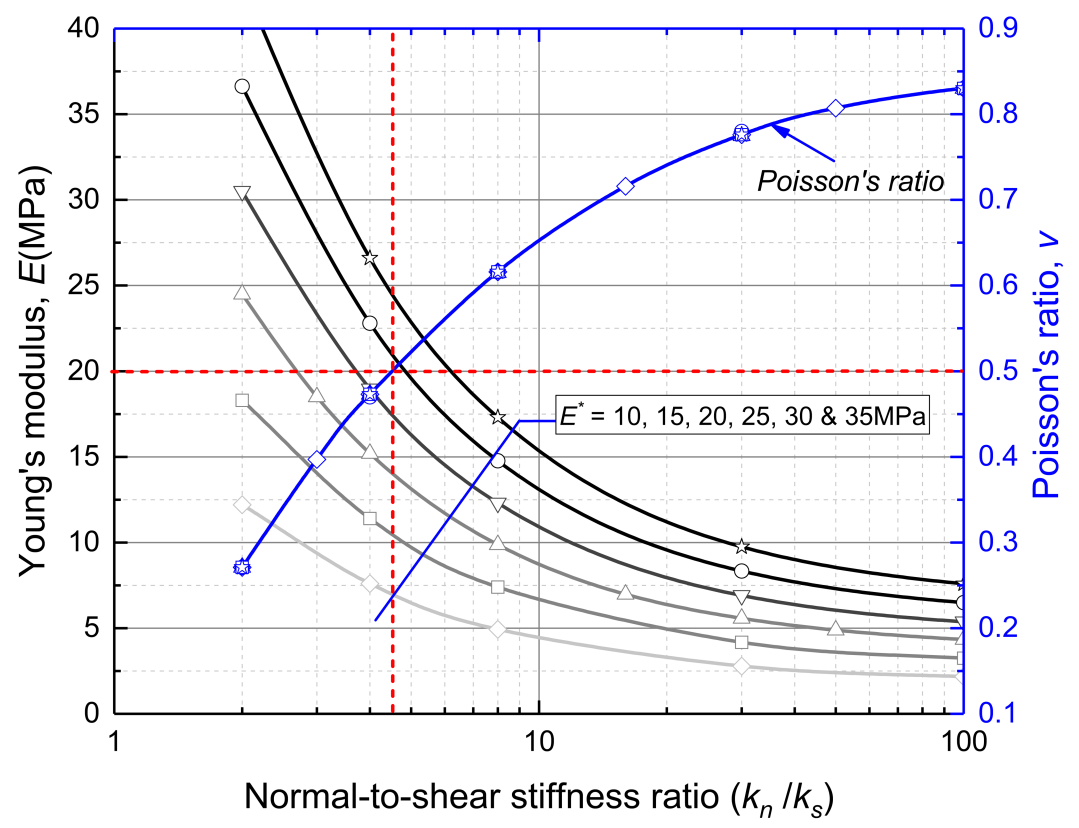

Fig. 11. A design chart for rubber tyre tensile test 


\section{CONCLUSIONS}

This paper presents a methodology for modelling the elastic behaviour of rubber tyres using three-dimensional DEM model. The linear contact bond model was used. It was found that DEM could simulate the rubber tyre replicating Young's modulus, Poisson's ratio and tensile strain relationships successfully based on tensile tests. The simulation results illustrate that $k_{\mathrm{n}} / k_{\mathrm{s}}$ (particle normal-to-shear stiffness ratio) and packing structure have a dominant effect on the specimen's Poisson's ratio.

Comparing to assemblies with FCC and HCP packing, a specimen with BCC packing could provide a Poisson's ratio of 0.5 for rubber tyres. Further, for BCC packing, Poisson's ratio decreases from 0.50 to 0.21 with changing the particle overlap, yielding to a transition point at an overlap of $5.87 \%$. However, particle overlap has a minimal effect on both $E$ and $v$ of FCC and HCP packing assemblies. For the particle size effect, when the transverse length $(D)$ to the particle radius $(R)$ ratio is larger than 33.3 , both $E$ and $v$ are constant. A particle radius of $0.3 \mathrm{~mm}$ could be a good choice to simulate a $10 \mathrm{~mm}$ transverse length rubber tyre considering computing efficiency. The effect of sample aspect ratio on both $E$ and $v$ is minimal.

Based on the above DEM research on rubber tyre strips, we could simulate different shapes (e.g. various lengths and aspect ratios) of rubber tyres according to different engineering requirements. Therefore, tyre chips and tyre shreds, irregular rubber buffings and granulated rubber tyres, even the complete tyres without steel that are difficult to calibrate experimentally, could now all be modelled numerically based on the rubber tyre strip DEM model proposed in this paper. This research has provided a methodology and a good direction for modelling rubber tyre reinforcement by DEM which could be extended to rubber-soil micromechanical investigations.

\section{NOTATION}

$\begin{array}{ll}v & \text { Sample Poisson's ratio } \\ \mu & \text { coefficient of inter-particle friction } \\ e_{t} & \text { transverse strain } \\ e_{l} & \text { longitudinal strain } \\ k_{\mathrm{n}} / k_{\mathrm{s}} & \text { normal-to-shear stiffness ratio } \\ c b_{\text {_tenf }} & \text { contact bond tensile strength } \\ c b_{\text {_shearf }} & \text { contact bond shear strength } \\ D & \text { transverse length after tension } \\ D_{0} & \text { transverse length before tension } \\ L & \text { longitudinal length after tension } \\ L_{0} & \text { longitudinal length before tension } \\ R & \text { Particle radius } \\ E & \text { Sample Young's modulus }\end{array}$


$E^{*} \quad$ Particle effective modulus

FCC face-centred-cubic packing

HCP hexagonal close-packed packing

BCC body-centred-cubic packing

Table 1 Input parameters of DEM elements for rubber tyre model

\begin{tabular}{cc}
\hline Parameter & Value \\
\hline Particle density $\left(\mathrm{kg} / \mathrm{m}^{3}\right)$ & 1100 \\
Coefficient of inter-particle friction $(\mu)$ & 0.2 \\
Particle effective modulus, $E^{*}(\mathrm{MPa})$ & 20 \\
Normal-to-shear stiffness ratio, $k_{\mathrm{n}} / k_{\mathrm{s}}$ & 4.5 \\
Tensile strength, $c b \_\operatorname{tenf}(\mathrm{N})$ & $2 \mathrm{e} 150$ \\
Shear strength, $c b \_s h \operatorname{searf}(\mathrm{N})$ & $2 \mathrm{e} 150$ \\
\hline
\end{tabular}

Table 2 Selection of $E^{*}$ and $k_{\mathrm{n}} / k_{\mathrm{s}}$ in rubber tyre numerical model

\begin{tabular}{ccc}
\hline$E^{*}(\mathrm{MPa})$ & $k_{\mathrm{n}} / k_{\mathrm{s}}$ & Range of strain $(\%)$ \\
\hline 33 & 4.6 & $0.0-2.2$ \\
23 & 4.6 & $2.2-4.5$ \\
18 & 4.6 & $4.5-8.0$ \\
11 & 4.6 & $8.0-15.0$ \\
\hline
\end{tabular}

\section{ACKNOWLEDGEMENTS}

The authors would like to thank the Ministry of Education of China and University College London (UCL) for their generous financial support (Grant no. 201508420167). They also thank Professor Matthew Coop at UCL for his valuable suggestions, which have helped to improve the quality of the paper significantly. The first author would also like to express gratitude to the University of Cambridge for providing opportunity to study at Cambridge Centre for Smart Infrastructure and Construction (CSIC) research group. 


\section{REFERENCES}

Andre, D., Iordanoff, I., Charles, J. \& Neauport, J. (2012). Discrete element method to simulate continuous material by using the cohesive beam model. Computer Methods in Applied Mechanics and Engineering Vols 213-216, 113-125.

Ahmad. F., Yahaya, A.S. \& Safari, A. (2016). Development of low-cost soil stabilization using recycled material. IOP Conf. Series: Materials Science and Engineering 136, 012003. doi:10.1088/1757-899X/136/1/012003

ASTM D 6270-98. (2008). Standard practice for use of scrap tires in civil engineering applications -ASTM D 6270-98 (reapproved in 2008). ASTM, W. Conshohocken, PA, p 19.

Bergado, D. T., Youwai, S. \& Rittirong, A. (2005). Strength and deformation characteristics of flat and cubical rubber tyre chip-sand mixtures. Géotechnique 55, No. 8, 603-606.

Chen, G., Schott, D.L. \& Lodewijks, G. (2016). Tensile test simulation of high-carbon steel by discrete element method. Engineering Computations: International Journal for ComputerAided Engineering and Software 33, No. 4, 1224-1245.

Eberhard, P. \& Gaugele, T. (2013). Simulation of cutting processes using mesh-free Lagrangian particle methods. Computational Mechanics 51, No. 3, 261-278.

Edinçliler, A., Baykal, G. \& Saygilı. (2010). Influence of different processing techniques on the mechanical properties of used tyres in embankment construction. Waste Management 30, $1073-1080$.

Edinçliler, A. \& Cagatay, A. (2013). Weak subgrade improvement with rubber fibre inclusions. Geosynthetics International 20, No. 1, 39-46.

Fleischmann, J.A., Drugan, W.J. \& Plesha, M.E. (2013). Discrete micromechanics derivation and DEM confirmation of the elastic moduli of isotropic particulate materials: Part I No particle rotation. Journal of the Mechanics and Physics of Solids 61, 1569-1584.

Fu, R., Coop, M.R. \& Li, X.Q. (2017). Influence of particle type on the mechanics of sandrubber mixtures. J. Geotech. Geoenviron. Eng., 143, No.9, 04017059.

Fu, R., Coop, M.R. \& Li, X.Q. (2014). The mechanics of compressive sand mixed with tyre rubber. Géotechnique Letters No. 4, 238-196.

Gaugele, T., Fleissner, F. \& Eberhard, P. (2008). Simulation of material test using mesh-free Lagrangian particle methods, Proceedings of the Institution of Mechanical Engineers, Part K: Journal of Multi-body Dynamics 222, No. 4, 327-337.

Gotteland, Ph., Lambert, S. \& Salot, Ch. (2008). Investigating the strength characteristics of tyre chips-sand mixtures for geo-cellular structure engineering. Proceedings of the International Workshop on Scrap Tire Derived Geomaterials - Opportunities and Challenges, IW-TDGM 2007, 351-361.

Heitkam S., Dreckhan, W., Titscher, T., Weaire, D., Kreuter, D.C., Hajnal, D., Piechon, F \& Frohlich, J. (2016). Elastic properties of solid material with various arrangements of spherical voids. European Journal of Mechanics -A/Solids 59, 252-264.

Hewson, P. (2005). Method for estimating tyre cornering stiffness from basic tyre information. Proc. IMechE Part D: J. Automobile Engineering 219, No.12, 1407-1412. https://doi.org/10.1243/095440705X35071

Itasca. PFC Version 5.0, updated Sep 07, 2018. 
Lee, C., Shin, H. \& Lee, J. S. (2014). Behavior of sand-rubber particle mixtures: Experimental observations and numerical simulations. International Journal for Numerical and Analytical Methods in Geomechanics 38, No. 16, 1651-1663.

Mills, B. \& McGinn, J. (2010). Design, Construction, and Performance of a Highway Embankment Failure Repaired with Tire-Derived Aggregate. Transportation Research Record: Journal of the Transportation Research Board No.2170, 90-99.

Naval, S., Kumar, A. \& Bansal, S. K. (2014). Model tests on footing resting on waste tire fiber reinforced granular soil. International Journal of Geotechnical Engineering 8, No. 4, 469476. http://dx.doi.org/10.1179/1938636213Z.00000000076

Oikonomou, N. \& Mavridou, S. (2009). The use of waste tyre rubber in civil engineering works. Sustainability of construction materials 213-238.

Perez, J. C.L, Kwok, C. Y. \& Senetakis, K. (2016). Effect of rubber size on the behaviour of sand-rubber mixtures: A numerical investigation. Computers and Geotechnics 80, 199-214. http://doi.org/10.1016/j.compgeo.2016.07.005

Ratrout, N.T. \& Mahmoud, I.A. (2006). Adequacy of the tensile/elongation test as a quality control criterion for vehicle tires. Polymer Testing 25, No. 5, 588-596.

http://doi.org/10.1016/j.polymertesting.2006.01.017

Takano, D., Chevalier, B. \& Otani, J. (2014). Experimental and numerical simulation of shear behavior on sand and tire chips. Computer Methods and Recent Advances in Geomechanics 1545-1550. http://doi.org/10.1201/b17435-273

Wang, C., Deng, A. \& Taheri, A. (2018). Three-dimensional discrete element modeling of direct shear test for granular rubber-sand. Computers and Geotechnics 97, 204-216.

Wang, Z.J, Jacobs, F. \& Ziegler, M. (2014). Visualization of load transfer behaviour between geogrid and sand using PFC2D. Geotextiles and Geomembranes 42, No.2, 83-90.

Yoon, Y.W. (2007). Engineering characteristics of tire treads for soil reinforcement. In: H. Hazarika and K. Yasuhara, eds. Proceedings of the International Workshop on Scrap Tire Derived Geomaterials - Opportunities and Challenges (IWTDGM 2007), Yokosuka. London: Taylor \& Francis. 